\title{
Рынок сжиженных углеводородов: правовое регулирование в России и мировой опыт
}

Смирнов Д.Л.*

Под сжиженными углеводородными газами (СУГ) понимаются легкие углеводороды - пропан, бутан и их смеси в различных пропорциях в зависимости от направлений и условий использования (далее именуются - сжиженный газ). Сжиженные углеводородные газы - это пропан, бутан и их смеси. СУГ используются для отопления и горячего водоснабжения помещений, как топливо для автономных газовых плит, горючее для автомобилей и сырье для химической промышленности. В среднем в России ежегодно выпускается около 7 млн т СУГ. Основные производители - АК СИБУР (36\%), ОАО «Газпром» (35\%) и нефтяные компании (29\%). На внутреннем рынке реализуется более $30 \%$ СУГ.'

От сжиженного газа зависят отопление и бытовые нужды 50 млн человек в 78 регионах России. Количество населения, использующего для этого природный газ, лишь на $35 \%$ больше. Сильнее остальных регионов от поставок сжиженного газа зависят Дальний Восток, Забайкалье, Сибирь, Северо-Запад, сельские районы Центральной России и Поволжья.

Поставки СУГ для бытовых нужд регулируются государством. С 1999 года для этого устанавливаются специальные ежемесячные квоты для производителей (балансовые задания) - как правило, пропорционально общим объемам выпуска. Объемы квот определяют региональные регулирующие организации, подчиненные губернаторам, исходя из установленных норм потребления на человека, реализуется газ через государственные газораспределительные организации (ГРО). Поставлять СУГ на экспорт производители могут только в случае, если они полностью выполняют балансовые задания.

Рынок СУГ в России характеризуется высокой степенью зарегулированности. На функционирование рынка СУГ оказывают влияние

- Смирнов Дмитрий Львович - магистр права, аспирант кафедры европейского права МГИМО (У) МИД России.

' Здесь и далее статистические сведения приводятся по данным Российского газового общества. См.: www.gazo.nu 
такие направления государственного регулирования, как ценообразование, система балансировки рынка СУГ, регулирование экспорта, налогообложение, антимонопольное регулирование, государственное регулирование в области промышленной безопасности, дотирование малообеспеченных слоев населения и др.

Причиной введения административных мер для обеспечения поставок СУГ для бытовых нужд населения явилось обострение положения со снабжением населения СУГ в конце 1999 г., обусловленное ростом мировых цен на СУГ и увеличением поставок на экспорт, при заниженной регулируемой оптовой цене, которая в то время составляла 390 руб./т и не покрывала затрат на производство СУГ. Для стабилизации поставок СУГ для бытовых нужд населения были приняты экстренные меры. Правительством РФ ставка экспортной пошлины на СУГ была повышена до 60 евро/т. Для стабилизации поставок сырья на газоперерабатывающие заводы и предприятия нефтехимии с 1 декабря 1999 года цены на него были увеличены и составили: на «нефтяной попутный газ» (ПНГ) - 150 руб./1000 куб. м, на широкие фракции легких углеводородов (ШФЛУ) - 350 руб./т. Одновременно Минэнерго России по согласованию с Минэкономики России был разработан баланс производства и потребления СУГ на декабрь 1999 г. и 2000 г. и установлены балансовые задания компаниям-производителям на производство и поставку СУГ для бытовых нужд, утвержден график прикрепления регионов к производителям. Правительством РФ также было установлено, что оформление поставок СУГ на экспорт осуществляется таможенными органами при условии представления производителями ресурсных справок, подтверждающих наличие у организаций, осуществляющих поставки СУГ на экспорт, указанной продукции в объемах, достаточных для экспорта, с учетом выполнения балансовых заданий. Функции по обеспечению поставок населению СУГ по государственным регулируемым ценам были возложены на ФГУП "СГ-транс». С 1 января 2000 года оптовая цена на СУГ для бытовых нужд была увеличена до 780 руб./т. В результате принятых мер поставки СУГ для бытовых нужд населения стабилизировались. С 4 aпреля 2000 года ставка вывозной таможенной пошлины на СУГ была снижена до 40 евро/т для создания условий для развития российских производителей СУГ и с учетом сезонности их потребления.

Отметим, что с 1 июля 2003 года система балансовых заданий заменена системой установки графиков поставок СУГ для бытовых нужд 
потребителям РФ и на экспорт для производителей СУГ и ресурсовладельцев.

Таким образом, сложилась существующая система обеспечения обязательных поставок СУГ для бытовых нужд населения (система балансовых заданий), основанная на мерах административного регулирования, которая, однако, имеет ряд недостатков. Основными из них являются:

- ослабление стимулов к развитию производства СУГ;

- отсутствие закрепления данного вида регулирования в действующем правовом поле;

- нарушение положений действующего таможенного законодательства, в частности Закона Российской Федерации «О государственном регулировании внешнеторговой деятельности» в части исполнения регламента;

- существующие значительные административные риски, снижающие эффективность данного механизма, связанные с непрозрачностью процедур разработки, утверждения и выполнения балансовых заданий.

Преодолев кризисную ситуацию 1999 г. с поставками СУГ населению мерами таможенно-тарифного и административного характера, Правительство поручило Минэкономразвития разработать предложения по вопросу либерализации рынка ПНГ и порядку регулирования цен на СУГ для коммунально-бытовых нужд населения.

Поэтому, в отличие от газовой отрасли России в целом, где Концепция реформирования еще не принята, а существуют лишь проекты в сфере рынка сжиженных углеводородов, для устранения недостатков государственного рс уулирования и обеспечения надежного и бесперебойного снабжения населения сжиженным газом для бытовых нужд, создания «... механизмов, ограничивающих рост цен на сжиженный газ для бытовых нужд и обеспечивающих социальную зашиту населения», а также создания экономических условий, «стимулирующих производство сжиженного газа и наполнение внутреннего рынка сжиженного газа (для различных целей, но в первую очередь для бытовых нужд)», была разработана «Концепция развития рынка сжиженного газа для бытовых нужд» (далее - Концепция). Концепция была одобрена распоряжением правительства РФ от 3 июля 2003 года № 908-р. ${ }^{2}$

Концепция определяет следующие задачи развития рынка СУГ для бытовых нужд:

2 www.gazo.ru/ru/main/document/concept 
1. Стимулирование производства сжиженного газа и рост его предложения на российских оптовом и розничном рынках сжиженного газа, в том числе путем:

- ликвидации избыточного государственного регулирования, сдерживаюшего развитие производства сжиженного газа; в частности, последовательный отказ от регулирования цен на нефтяной попутный газ, оптовой цены на сжиженный газ для бытовых нужд (и снятие этой социальной нагрузки с производителей сжиженного газа) и от системы балансовых заданий;

- регулирования инструментов экономического воздействия на производителей сжиженного газа с целью выравнивания экономических условий экспорта сжиженного газа и его реализации на внутреннем рынке, а также выравнивания условий хозяйственной деятельности на оптовом рынке сжиженного газа с учетом поставки газа населению для бытовых нужд и прочим потребителям;

- развития системы использования (утилизации) газов, полученных при добыче углеводородов;

- развития системы доступа производителей сжнженного газа к рынкам продуктов газопереработки.

2. Реализация механизмов ограничения роста цен на сжиженный газ, в том числе путем:

- стимулирования и развития конкуренции на оптовом и розничном рынках сжиженного газа;

- повышения открытости торговли, создания единых механизмов ценообразования для участников рынков сжиженного газа (оптового и розничного);

- контроля (по крайней мере, на первом этапе) за уровнем розничных цен на сжиженный газ для бытовых нужд;

3. Развитие и дальнейшее совершенствование механизмов социальной защиты малообеспеченных слоев населения.

Согласно Концепции, реформирование рынка СУГ предполагается осуществлять в 2 этапа. На первом этапе предстоит создать стимулы для дальнейшего развития производства СУГ, что позволит наполнить внутренний рынок и отменить государственное регулирование оптового рынка СУГ с учетом развития системы адресных субсидий. Этим будут созданы необходимые условия для дальнейшего проведения либерализации розничных рынков на втором этапе.

Основные меры, предлагаемые Концепцией на первом этапе (ориентировочно до 2005 г.): 
- отмена государственного регулирования цен на ПНГ, принятие системы четких лицензионных обязательств в отношении газов, полученных при добыче углеводородов;

- принятие комплекса мер по стимулированию газопереработки и облегчению доступа на рынки продуктов газопереработки (в частности, усиление антимонопольного контроля за функционированием транспортной инфраструктуры СУГ, а также решение проблем доступа к магистральным газопроводам, что будет иметь большое значение для поставциков сухого газа);

- поэтапная отмена регулирования оптовых цен на СУГ;

- усовершенствование к 2005 г. механизмов предоставления адресных субсидий;

- функционирование вплоть до отмены регулирования оптовых цен системы балансировки производства, транспорта, внутреннего потребления и экспорта СУГ посредством формирования графика поставок СУГ для бытовых нужд;

- создание системы информационно-аналитической поддержки, включающей в себя, в частности, публикацию информации об уровне цен на сжиженный газ, корректировку форм статистической отчетности о производстве и потреблении СУГ в РФ и регулярную публикацию сводных данных по этой отчетности;

- отмена привязки вывозной таможенной пошлины для СУГ к размеру вывозной таможенной пошлины на нефть; включение СУГ в утверждаемый Правительством РФ список видов товаров и услуг, экспорт которых может быть ограничен;

- сохранение регулирования розничных цен на СУГ в рамках субъектов РФ, разработка методик формирования розничных цен на СУГ в регионах, а также обеспечение механизмов создания резервов сжиженного газа на всех уровнях (производство, транспорт, распределение);

- пересмотр и унификация норм потребления, устанавливаемых как на региональном, так и на федеральном уровне.

Предполагается, что первый этап завершится отменой государственного регулирования оптовой цены на сжиженный газ для бытовых нужд.

Основные меры, предлагаемые Концепцией на втором этапе (ориентировочно с 2005 по 2008-2010 гг.):

- продолжение реализации мер по стимулированию газопереработки и облегчению доступа на рынки продуктов газопереработки путем совершенствования системы доступа к магистральным газопроводам; 
- внедрение гибкой системы регулирования вывозных таможенных пошлин для СУГ в зависимости от степени насыщения внутреннего рынка СУГ и уровня цен на нем в целях «оптимальной балансировки объемов сжиженного газа, направляемого на внутренние рынки и на экспорт».

Предполагается, что к окончанйю второго этапа будет сформирован конкурентный оптовый рынок сжиженного газа и созданы предпосылки для отмены государственного регулирования розничных цен на СУГ для коммунально-бытовых нужд. Второй этап должен завершиться отменой государственного регулирования розничных цен на сжиженный газ для бытовых нужд.

Из Концепции развития рынка сжиженного газа для бытовых нужд в РФ понятно, что она является попыткой осуществить дерегулирование этого рынка, а в частности - ценообразования на рынке. В ходе проведенного анализа данной Концепции были выявлены следующие основные проблемные моменты.

Во-первых:

- сушествует целый комплекс причин, которые ведут к необходимости осуществить дерегулирование рынка СУГ или, вернее, изменить способ регулирования рынка, а именно перевести его на рыночные основы и заменить неэффективный способ регулирования цены на другие способы регулирования;

- существует угроза возникновения дефицита СУГ для населения;

- возможно снижение качества обслуживания населения и увеличение вероятности аварий;

- остро стоят вопросы безопасности.

Во-вторых, существует необходимость защиты малообеспеченных потребителей и предоставления им адресных субсидий.

В-третьих, так же остро стоит общий вопрос недостаточности стимулирования развития рынка СУГ, и в частности использования автогаза.

Возникает один из главных вопросов: решат ли меры, предлагаемые концепцией, проблемы в этом сегменте экономики?

Вопросы разработки технических стандартов хранения, транспортировки, торговли и использования СУГ (LPG), лоббирования его использования в мире в основном решаются при помоши норм, которые разрабатываются Ассоциациями СУГ. В законах, которые регулируют СУГ, практически всегда делается отсылка к кодексам, правилам, нор- 
мам, техническим стандартам, которые разрабатываются соответствующими ассоциациями.

Существует Всемирная ассоциация СУГ. ${ }^{3} \mathrm{~B}$ нее входят Европейская ассоциация, Ибероамериканская, Австралийская, Ассоциация США, Ассоциация Канады, Конфедерация индийской промышленности СУГ, Корейская корпорация по газовой безопасности, а также другие национальные ассоциации и ведущие компании этой отрасли.

Так как в эти ассоциации входят компании, профессионально заинтересованные в развитин СУГ в соответствуюших странах и в мире в целом, то можно с большой долей уверенности опираться в свонх предложениях на их опыт и разработки.

Необходимо отметить, что в России такая ассоциация отсутствует. Несомненна потребность в объединении заинтересованных сторон в вопросе продвижения своих интересов на рынке СУГ. Также очень важным является то, что от наличия подобного объединения зависит безопасность использования СУГ.

\section{Опыт CША}

1. Прежде всего остановимся на дерегулировании и переходе на рыночные основы. Здесь следует обратиться к опыту США 4 , где с 1973 по 1981 гг. Федеральное правительство регулировало цену и распределение пропана в стране, что привело к негативным последствиям для промышленности и потребителей. ${ }^{5}$

Таким образом, в начале 70-x rr. США столкнулись со схожими проблемами, которые в настоящий момент имеются в России (эти

См.: www.worldlpgas.com

+ Здесь и далее информация по США приводится на основе использованных материалов архива Национальной Ассоциации СУГ США.

"Для справки: Для того чтобы оценить ситуацию в целом в США на рынке СУГ, приведем лишь некоторые данные.

В начале 70-х гг. в США сушествовало более 25000 розничных точек продажи СУГ, 8000-9000 станций хранения и распределения, 400000 км продуктопроводов, более 4 млд галлонов емкостей для СУГ, 25000 транспортных грузовиков, 22000 железнодорожных цистерн, 400 барж и танкеров. СУГ в основном потреблялся на фермах, в ма.бых населенных пунктах и в сельской местности. Он использовался для приготовления пици, подогрева воды, отопления домов и др. Более половины ферм использовали СУГ для сушки зерновых и в других с/х целях. На СУГ работали трактора, грузовики, насосы, генераторы и другая техника. Также СУГ использовался в ресторанном и гостиничном бизнесе. В промышленности СУГ использовался для пайки, сварки, обжига керамики, литья под давлением, объемной штамповки на падающем мопоге, резки металла, плавки стекла, отжига, вулканизации и в других целях. Всего иа СУГ в США на тот момент приходилось около $3 \%$ всей потребляемой энергии. 
проблемы в числе прочего были вызваны недостатком профессиональных знаний и понимания отрасли СУГ среди правительственных чиновников, хотя они и искренне стремились улучшить положение вещей; но, как показала практика, этого оказалось недостаточно):

- сбои в поставках и дефицит пропана для коммунально-бытовых нужд и сельского хозяйства (в США это происходило из-за перенаправления потоков пропана, замены им нехватки природного газа в промышленности. В России пропан также перенаправляется в нефтехимию или на экспорт, и как в США, так и в России это происходит из-за того, что он покупается по более высокой цене различными посредниками через «серые схемы», которые затем продают его заинтересованным лицам, промышленным предприятиям и другим желающим. В итоге пропан не доходит до потребителей, использующих его в бытовых целях, поскольку они не способны покупать СУГ по завышенной цене);

- отсутствие различий в регулировании цены зимой и летом (механизм регулирования не позволял делать значительные запасы СУГ летом и продавать его затем зимой - в период, когда потребляется $2 / 3$ всеге СУГ);

- рост оптовых цен и фиксация розничных цен привели к банкротству многих розничных продавцов (цены продавцов и уровень прибыли были заморожены в США на уровне 15 мая 1973 года $^{6}$, схожая ситуация может произойти в России на переходном этапе, предусмотренном в концепции, когда оптовые цены уже не будут регулироваться, а розничные цены еше будут устанавливаться субъектами Федерации);

- повышение цены СУГ из-за сложности регулирования (сложность механизма регулирования, необходимость вести сложный учет и базу данных, установленную сверху, привели к возрастанию стоимости СУТ, и это легло тяжелым бременем особенно на малые предприятия, которым потребовалось нанимать дополнительно бухгалтеров, кассиров, юристов и расходовать больше времени. Для России это особенно опасно в связи с дополнительной нагрузкой на предприятия со стороны коррумпированных чиновников. Механизм регулирования должен быть максимально прозрачным и простым, предусматривать минимум формальностей, перекрестных платежей и отчетности);

${ }^{6}$ The Emergency Petroleum Allocation Act, 1973. Pub. L. 93-159 (November 30, 1973). 
- дублирование, противоречия, задержки (само регулирование осуществлялось достаточно хаотично, т.к. Совет по прожиточным ценам $^{7}$ (Cost of Living Council) совместно со Службой по налогам (Internal Revenue Service) передавал законопроекты в Федеральную энергетическую службу (Federal Energy Office), затем они поступали в Федеральную администрацию по энергетике (Federal Energy Administration) и оттуда, наконец, в Департамент (Министерство) энергетики (Department of Energy) - это привело к тому, что «Порядок ценообразования розничными торговцами СУГ» был принят в $1976 \Gamma^{8}$, т.е. через три года после того как фактически начало применяться регулирование ценообразования. Можно привести и много других примеров. Решения зачастую противоречили сложившейся практике и не учитывали советов экспертов);

- сложности в планировании (постоянное изменение в регулировании, принятие норм, правил и толкований осложняет планирование поставок, создания хранилищ, транспортных мощностей);

- недостаточная ценовая гибкость в регионах (при установлении цены недостаточно учитывались различия в регионах и ситуация для различных поставщиков и продавцов, что ставило их в неравное положение. Для России с ее территорией это особенно значительно).

Национальной ассоциации СУГ США ${ }^{9}$ удалось убедить федеральное правительство США в необходимости устранить регулирование, и оно было отменено.

\section{Результаты отмены регулирования:}

1. Рыночные силы сбалансировали спрос и предложение и обеспечили достаточное количество СУГ.

Министерство юстиции США 5 июня 1978 года сделало доклад "Simplification of Crude Oil Price Controls", в котором содержалось об-

${ }^{7}$ Перевод дословный. - Д.С.

${ }^{8}$ Compliance Guide for Propane Pricing by Independent Resellers, 1977.

'Для справки: Начиональная ассоицачия СУГ США была образована в 1931 г. В ее состав входит около 4000 козианий США и 44 ассочияици СУГ отдельньх Штатов. Национальная ассоциация СУГ США является вертикально интегрированным профессиональным объединением, куда входят оптовые и розничные торговцы СУГ, производители и продавцы оборудования, производители баллонов и крупных емкостей, транспортные компании и др.

В 1974 г. в целях представления интересов Ассоциации и других участников отрасли при государственном регулировании распределения нефтепродуктов и ценообразования был образован Национальный комитет по распределению пропана и регулированию ценообразования, который стал работать от имени всей отрасли. 
рашение к Департаменту энергетики США о том, что «только саморегулирование спроса и предложения на рынке, где господствует конкуренция, может в должной мере защитить потребителя и обеспечить достаточное количество товаров по разумным ценам». Также отмечалось, что «нефтегазовая промышленность слишком многоплановая и динамичная и поэтому не поддается всеобъемлюшему регулированию в течение длительного периода». Конкуренция между взаимозаменяемыми товарами в значительно большей мере ограничивает рост цен на СУГ, чем неэффективное централизованное регулирование.

2. В промышленности наметилось оживление по увеличению производства и его совершенствованию, увеличилась торговорозничная сеть.

Предложение на рынке возросло в связи с тем, что спрос стал определяться на ценовой основе, а не на произвольных решениях правительства относительно того, кому и сколько потреблять и по какой цене. Возросла конкуренция между посредниками, т.к. они смогли выбирать поставщиков, основываясь на различиях в предлагаемой цене. Предложение на розничном уровне тоже выросло. Появился больший выбор продавцов.

3. Были устранены затраты, связанные с осуществлением регулирования (трансакционные бюрократические издержки). Это привело к повышению производительности труда в отрасли, что повысило качество предоставляемых услуг населению и снизило цены.

Появились стимулы к инвестированию в отрасль. В большинстве случаев действующий государственный механизм регулирования не позволяет окупать затраты на инвестиции, от чего страдают покупатели, т.к. стоимость товара не снижается.

Что касается России, то можно говорить о возможности использования опыта США, адаптирования его по возможности к российским реалиям и отказа от неэффективного способа регулирования рынка СУГ (система балансовых заданий, оптовое и розничное регулирование цен СУГ для населения).

Необходимо постараться избежать отмены регулирования оптовой цены при сохранении фиксированной розничной цены.

Нужно учитывать сезонные колебания цены на СУГ. В целях защиты потребителей и рынка можно, например, создать систему хранилищ СУГ на базе Государственного агентства по материальным резервам, которое профессионально занимается вопросами хранения. Заку- 
пать СУГ в период минимальных цен, а в случаях серьезного колебания цены позволить ему участвовать в качестве продавца на рынке, как это сейчас происходит на рынке сахара.

Точно определить воздействие отмены ценового регулирования на изменение цены СУГ в России невозможно, но оно, вероятно, будет не слишком велико, учитывая тот факт, что анализ, проведенный АК СИБУР (обеспечивает около 30\% балансовых заданий), показывает, что потребители получают СУГ по ценам не ниже рыночных. Так, «Чувашсетьгаз» отпускает СУГ населению по 7,26 тыс. руб. за тонну (за вычетом закупочной цены и транспортных издержек у ГРО остается 4,78 тыс. руб.), а «Томскоблгаз» - по 11,54 тыс. руб. за тонну (разница - 8,2 тыс. руб.). «Хотелось бы получить объяснения ГРО, откуда берутся такие цены, - удивляются в СИБУРе. - Кроме того, объем квот с 2003 г. вырос на 30\%, хотя нормы потребления остались прежними, а число квартир, газифицированных сжиженным газом, уменьшилось: «Газпром» успешно реализует программу газификации природным

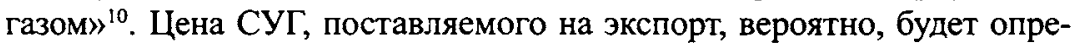
делять внутреннюю цену. Если ставка вывозной таможенной поилины на СУГ не будет зависеть от ставки вывозной поилины на нефть и учитывать сезонные колебания чены, то чена будет мало отличаться от ныне сложивиейся чены на свободном оптовом рынке. Конкуренция между поставциками СУГ и поставциками альтернативного топлива (бензин, керосин, природный газ, электричество) будет основным фактором, определяющим чену СУГ.

Несомненно, что проблема наличия СУГ для населения будет минимизирована, если не совсем устранена. Можно будет осуществлять долгосрочное планирование и инвестиции в этой сфере.

Еще одним аргументом, подтверждающим необходимость отмены административного регулирования цены и перехода на рыночные основы служит пример Австралии.

Ценового административного регулирования на рынке СУГ Австралии нет с 1991 г. Цена устанавливается между производителями и продавцами путем переговоров и отражает мировые цены на СУГ. В общем цены привязаны к ежемесячной цене, устанавливаемой крупнейшим производителем - Саудовской Аравией.

${ }^{10}$ Федеральная служба по тарифам рассмотрит вопрос о повышении закупочной цены по государственным балансовым заданиям на производство СУГ (Комнерсанm, 19.01.2005). 
В прошлом Садовская Аравия основывала свой рынок преимущественно на основе нефтяного паритета. Однако в октябре 1994 года Саудовская Аравия отказалась от привязки к цене на сырую нефть и стала основываться на подходе к ценообразованию на СУГ, который отражает рынок СУГ сам по себе. Каждый месяц проводятся тендеры, и Саудовская Аравия устанавливает цену с учетом информации по тендерам и других факторов.

Этот подход к ценообразованию означает вероятность значительных периодических ценовых скачков. Например, за период с июля 1994 года по февраль 1995 года цена на пропан в Саудовской Аравии возросла с 121,5 долл. США за тонну до 230,0 долл. США за тонну. Это привело к сушественному увеличению оптовой и розничной цены на СУГ в Австралии в начале 1995 г.

Закономерен поэтому вопрос любого потребителя: «Почему цена на такой местный товар, как СУТ, должна зависеть от мировой цены?». Правительство Австралии дает на него простой ответ: «Если цена в Австралии будет ниже мировой цены, то австралийский СУГ будет экспортироваться». Это не единственная причина. Как показал опыт США и Австралии, административное регулирование цены на СУГ сказывается негативно на инвестициях в разработку, добычу и переработку.

Однако отмена ценового административного регулирования не означает отмены регулирования рынка СУГ вообще и передачу его на произвол рыночных сил. Это «дерегулирование» предполагает на самом деле наличие других, более эффективных способов регулирования.

После отмены административного регулирования ценообразования и распределения СУГ появляются вопросы, без решения которых все пренмущества такого дерегулирования могут быть сведены на нет:

- обеспечение конкуренции на рынке СУГ,

- ужесточение требований по разделению видов деятельности компаний,

- установление конкурентного рынка путем разделения компаний владельцев транспортных сетей,

- обеспечение доступа к транспортным мощностям,

- установление структуры тарифов за транспортировку газа, отражающую реальные затраты,

- обеспечение прозрачного ценообразования, 
- обеспечение возможности недискриминационного получения лицензий,

- обеспечение безопасности производства, транспортировки, хранения, распространения СУГ на основе технических норм, их разработка и контроль за выполнением,

- обеспечение защиты прав потребителей,

- расширение при необходимости полномочий регулирующих органов в целях решения этих вопросов.

Фактически следует говорить о замене прямого административного регулирования ценообразования на СУГ и его распределения на способ регулирования, который можно назвать «способ регулирования конкуренции и прав потребителей».

Так, в Австралии существует Австралийская комиссия по конкуренции и правам потребителей (Australian Competition and Consumer Commission - ACCC) ${ }^{11}$, которая фактически занимается мониторингом цен на СУГ.

АССС отвечает за расследование поведения, несовместимого с конкуренцией на региональных рынках СУГ. Комиссия может в соответствии с Законом об обычаях торговли (the Trade Practices Act) предпринять действия по восстановлению конкурентной среды, если имеет место поведение, нарушающее конкуренцию.

Комиссия следит за ценами на бензин, дизтопливо и СУГ на 4000 точках продаж по всей Автралии. Комиссия также обладает правом проводить время от времени проверки в труднодоступных областях и расследует жалобы относительно изменения цены при помощи специального механизма GST Price Line.

В связи с вышесказанным было бы наиболее целесообразным для решения этих вопросов обратиться к опыту Европейских Сообшеств, учитывая высокую социальную ориентированность политики, проводимую этим объединением.

В Европейских Сообществах также отсутствует прямое административное регулирование ценообразования, но, также как и в Австралии, можно говорить о тенденции регулирования этого рынка под девизом обеспечения конкуренции на рынке и зашиты прав потребителей.

В настояшее время гармонизация регулирования рынков природного газа и электричества находится в сфере энергетики в ЕС на наибо-

${ }^{11}$ Информацию о Комиссии см.: www.accc.gov.au 
лее продвинутой стадии. Учитывая наличие в ЕС «Общей энергетической политики», можно говорить, что принципы регулирования рынка природного газа и электричества имеют тенденцию к распространению и на другие рынки.

На примере газовой и электроэнергетической отраслей, которые являются «локомотивом» либерализации энергетики, видно, что ЕС проводит либерализацию энергетической сферы все более быстрыми темпами и в скором времени, вероятно, аналогично будут регулироваться и другие сектора энергетики. Вместе с тем эти процессы нельзя назвать либерализацией в классическом понимании, так как они сопровождаются:

- установлением строгих правил по разделению управления вертикально интегрированных компаний,

- усилением контрольных полномочий регулирующих органов.

На государства налагаются новые обязанности по защите прав потребителей и окружающей среды. В связи с этим национальные регулирующие органы наделяются более широкой компетенцией. По новым правилам они осуществляют, в частности, контроль за обеспечением недискриминационного режима и эффективной конкуренции во всех сегментах рынка, изменение и утверждение тарифов, урегулируют споры в досудебном порядке.

В России следует оченить опыт ЕС и, вероятно, следует воспользоваться определенными положительными решениями:

- ужесточить требования по разделению видов деятельности;

- обеспечить доступ третьей стороны к важнейиим производственньмм мочностям ${ }^{2}$;

12 Для интерпретации американской концепции важнейших производственных мощностей в Суде ЕС смотри мнение Генерального Адвоката Якобса в деле Bronner Дело C-7/97 [1998] ECR I-7791, параграф 47.

Ее важность для секторов энергетики, привязанных к сетям, непосредственно очевидна, и, действительно, в ставшем поворотным пунктом 1973 года деле Otter Tail Верховный Суд США постановил, что Otter Tail, предприятие по комплексной подаче электроэнергии, было обязано переориентировать оптовые поставки электроэнергии, предоставляемые другой компанией, на два муниципалитета, которые стремились заниматься розничным распределением электроэнергии. См.: L. Hancher and P. Trepte, 13 Eur. Comp. LR 149 - 60 (1992); R. Lock, 2 Util. L. Rev. 18 (1991).

Ряд критериев, которые используются судами либо другими органами принуждения для определения того, следует ли налагать обязательство на «доминирующую» фирму в целях распределения ее активов с конкурентами, с тем чтобы вынудить их к конкуренции см. в книге I. Ritter, W. Braun, and F. Rawlinson, European Competition Law: a Practitioner's Guide (2nd edn., 2000). P. 383. 
- способствовать установлению конкурентного рынка путем разделения компаний - владельчев транспортных сетей;

- обеспечить установление структуры тарифов за транспортировку газа, отражсающую реальные затраты;

- обеспечить прозрачность ченообразования;

- расиирить полномочия регулирующих органов в челях защиты прав потребителей.

В челом необходимо сделать вывод о том, что отмена прямого административного ченового регулирования и распределения в разлиных странах не означает отмену или отказ от регулирования вообще, а скорее означает замену неэффективного способа регулирования чены и распределения на более эффективный, который мы назвали выне "способом регулирования конкурениии и прав потребителей". который в конечном итоге позволяет влиять и на уровень чен и ведет не к ослаблению, а к усилению контрольных полномочий регулируюцих органов, но уже на другом качественном уровне.

Что касается возможности использования зарубежного опыта, то как единое целое ни одна модель реформирования газовой отрасли и газового рынка, безусловно, не может быть применена к российским условиям. С другой стороны, общие принципы реформирования рынков и отдельные инструменты вполне приемлемы для российских условий. Важны комплексный подход, этапность и последовательность преобразований и выстраивание гибкой системы управления рисками, сопутствуюшими реформам, при этом сами по себе рыночные реформы в отрасли не представляют собой угрозу надежности поставок СУГ. 